\title{
Predictors of Success in the Treatment of Obstructive Sleep Apnea Syndrome with Mandibular Repositioning Appliance: A Systematic Review
}

\author{
Fernanda Saffer ${ }^{1}$ José Faibes Lubianca Neto ${ }^{2}$ Cassiano Rösing ${ }^{3}$ Caroline Dias ${ }^{1} \quad$ Luciane Closs $^{1}$ \\ ${ }^{1}$ Department of Orthodontics, ULBRA, Canoas, Brazil \\ 2 Department of Clinical Surgery, UFSCPA, Porto Alegre, Brazil \\ ${ }^{3}$ Department of Periodontology, UFRGS, Porto Alegre, Brazil \\ Address for correspondence Caroline Dias, Department of \\ Orthodontics, School of Dentistry, ULBRA, Av. Farroupilha, 8001, \\ Canoas 92425-900, Brazil (e-mail: carolinedias@terra.com.br).
}

Int Arch Otorhinolaryngol 2015;19:80-85.

\begin{abstract}
Introduction Obstructive sleep apnea syndrome affects up to $4 \%$ of middle-aged men and $2 \%$ of adult women. It is associated with obesity.

Objective The objective of this article is to review the literature to determine which factors best correlate with treatment success in patients with obstructive sleep apnea syndrome treated with a mandibular repositioning appliance.

Data Synthesis A search was performed of the PubMed, Cochrane, Lilacs, Scielo, and Web of Science databases of articles published from January 1988 to January 2012. Two review authors independently collected data and assessed trial quality. Sixty-nine articles were selected from PubMed and 1 from Cochrane library. Of these, 42 were excluded based on the title and abstract, and 27 were retrieved for complete reading. A total of 13 articles and 1 systematic review were considered eligible for further review and inclusion in this study: 6 studies evaluated anthropomorphic and physiologic factors, 3 articles addressed cephalometric and anatomic factors, and 4 studies

Keywords

- systematic review

- sleep apnea syndrome

- obstructive sleep apnea syndrome evaluated variables related to mandibular repositioning appliance design and activation. All the studies evaluated had low to moderate methodologic quality and were not able to support evidence on prediction of treatment success.

Conclusion Based on this systematic review on obstructive sleep apnea syndrome treatment, it remains unclear which predictive factors can be used with confidence to select patients suitable for treatment with a mandibular repositioning appliance.
\end{abstract}

\section{Introduction}

According to the American Academy of Sleep Medicine Task Force, obstructive sleep apnea is the complete interruption of airflow to the airway for at least 10 seconds. If the anatomical obstacle or the functional change leads to complete prevention of the inspiratory flow, the patient experiences oxygen desaturation and microarousals, which is defined as hypopnea. ${ }^{1,2}$

received

July 6, 2014

accepted after revision

September 2, 2014

published online

October 17, 2014
DOI http://dx.doi.org/

DOI. 10.1055/s-0034-1393957.

ISSN $1809-9777$.
Obstructive sleep apnea syndrome (OSAS) affects up to $4 \%$ of middle-aged men and $2 \%$ of adult women. Its prevalence increases with age until approximately the seventh and eighth decades of life; it is more frequent in men and postmenopausal women. The prevalence of OSAS, defined by Apnea-Hypopnea Index (AHI) frequency and the presence of hypersomnolence, has been estimated to range from 1.2 to $7.5 \%{ }^{3}$ It is strongly associated with

Copyright $\odot 2015$ by Thieme Publicações License terms Ltda, Rio de Janeiro, Brazil

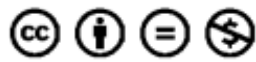


obesity, and there is also evidence of a hereditary component of OSAS. ${ }^{4-7}$

OSAS has become a concern in clinical practice because of its prevalence and because it is a potential risk factor for neurologic diseases such as cerebrovascular accidents, cardiovascular hypertension, acute myocardial infarction, and congestive heart failure, in addition to obesity and metabolic syndrome. However, it remains underdiagnosed. ${ }^{1,2,8-10}$

There are many treatment options for OSAS, including positive airway pressure therapy, oral appliances, and surgery. Oral appliances may be used in patients with mild to moderate OSAS and in those with more severe disease who are unable to tolerate continuous positive airway pressure therapy. ${ }^{11}$ Thus, the objective of this article is to review the literature to determine which factors best correlate with treatment success in patients with OSAS treated with a mandibular repositioning appliance (MRA).

\section{Review of Literature}

MRAs, originally derived from functional dental appliances, are used during sleep to advance the mandible and thus prevent the collapse of oropharynx tissues and tongue base, thereby reducing events of upper airway obstruction. Because they are simple and portable, do not use electricity, and are relatively low cost, they are considered an alternative to the treatment of OSAS. MRAs present favorable results quickly. ${ }^{1-13}$

The clinical diagnosis of OSAS is confirmed by polysomnography (PSG), which assesses the parameters of quality, architecture, and sleep continuity; nasal/oral airflow; qualitative and quantitative measure of respiratory effort; oxyhemoglobin saturation; electrocardiogram; and position of the body during sleep. ${ }^{1,12,14}$

The PSG quantifies respiratory events per hour of sleep, and AHI confirms the diagnosis. This index is the number of times the air passage is blocked (apnea) or reduced (hypopnea) over 10 seconds each hour of sleep. An AHI of 5 to 15 events per hour is defined as mild apnea; 16 to 30 , moderate apnea; and severe apnea, more than 30.5,12

According to anthropometric and physiologic predictors, OSAS is a common disease in the middle-aged population, in general affecting both males and females. ${ }^{2}$ Postmenopausal women may have OSAS as frequently as men. Obesity is a known risk factor directly related to OSAS. ${ }^{13}$, Obese individuals with OSAS have a higher fat volume and increase in cervical soft tissue structures on the airway, causing a reduction in size and alterations in the function of the respiratory muscles, promoting airflow obstruction. ${ }^{8-10}$

The respiratory problems associated with OSAS result from different anatomical and pathophysiological changes, which make it difficult to establish a single treatment that covers all cases. One conventional treatment is the MRA, which generally requires 4 weeks of adaptation to the device followed by 2 to 3 months of stepwise mandibular advancement (titration of the device) to maximize the acceptance of the appliance. A mandibular advancement of 50 to $75 \%$ of the maximum voluntary protrusion of the individual has been associated with favorable treatment results. ${ }^{11-13}$ The main difficulty is to achieve an adequate mandibular advancement without causing discomfort to the patient during the first night of use.

\section{Inclusion Criteria for Studies}

\section{Type of Study}

We reviewed published randomized controlled trials with experimental and control group addressing the research question: which factors best correlate with treatment success in patients with obstructive sleep apnea syndrome treated with a mandibular repositioning appliance.

\section{Type of Participants}

Studies with participants of both genders, over 16 years of age, with a diagnosis of OSAS, and with more than five apneas/hypopneas per hour of sleep were included.

\section{Type of Intervention}

The treatment group included studies that reported treatment with any MRA for OSAS; the control group included studies that reported OSAS treatments using another intervention (surgical or nonsurgical) or no intervention.

\section{Search Methods}

Two reviewers independently performed an electronic search databases of PubMed, Web of Science, Cochrane Library, Lilacs, and Scielo. The terms used in the literature review were: [(sleep apnea OR sleep apnoea OR obstructive sleep apnea OR obstructive sleep apnoea OR sleep apnea syndrome OR sleep apnoea syndrome OR apneic $O R$ apnoea $O R$ respiratory disturbance $O R$ sleep disorder breathing OR upper airway resistance syndrome) AND (mandibular repositioning appliance OR mandibular advancement device $O R$ oral appliance $O R$ mandibular device $O R$ anterior mandibular positioner OR mandibular splint OR oral appliance therapy OR intraoral sleep apnea devices OR oral jawpositioning appliance $O R$ intraoral positioning appliance $O R$ occlusal splint OR anteriorly titratable mandibular positioner OR adjustable oral appliance OR mandibular advancement splint $O R$ mandibular protruding device OR mandibular advancing appliance $O R$ oral jaw positioning appliance OR titratable oral appliance $O R$ oral vestibular shield $O R$ intraoral protrusive appliance)] AND (Randomized Clinical Trial AND English)]. The electronic search was from January 1988 to January 2012, with language restriction (English only). Two review authors conducted the electronic search independently.

\section{Data Extraction}

Primary outcomes include AHI. Secondary outcomes included other parameters of PSG, such as quality, architecture, and sleep continuity; nasal/oral airflow; quality and quantity measurement of respiratory effort; saturation of oxyhemoglobin; oxygen desaturation; body position; quality of life; and cognitive function.

\section{Data Analysis}

The selection of the studies took place in three phases. First, articles were selected from PubMed, followed by articles from 
82 Treatment of Obstructive Sleep Apnea Syndrome Saffer et al.

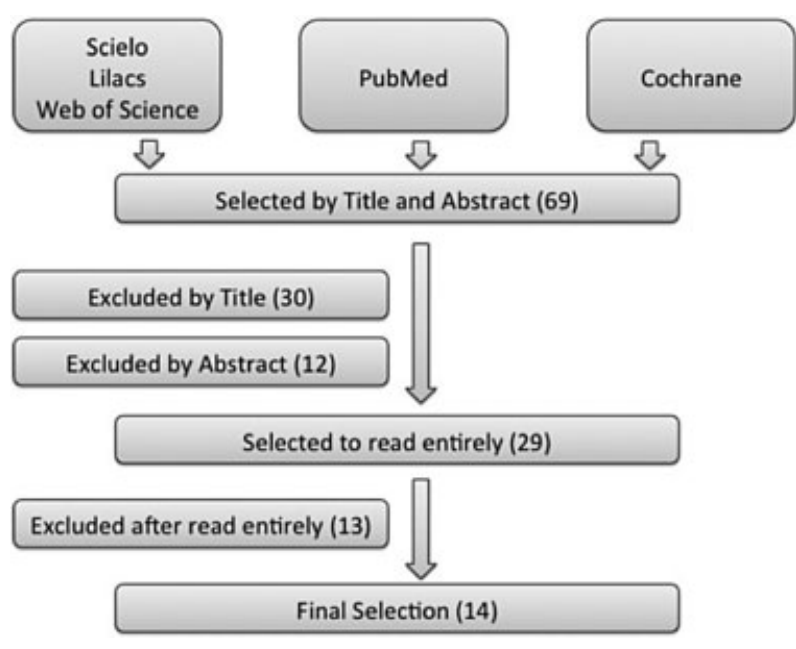

Fig. 1 Flowchart.

other electronic databases using the search terms mentioned previously. From these and based on the information provided in the title and the abstract, examiners selected the articles to read the entire text. Then, articles in which predictive factors of MRA treatment were possibly discussed were selected.

The grading of evidence from selected studies was also performed by the same two independent reviewers according to slight modification of the criteria and classified according to sample size calculation, randomization, clear definition of the inclusion and/or exclusion criteria, follow-up completion (and reasons for withdrawal in each study group were speci- fied), experimental and control group comparable at baseline, presence of blinding, appropriate statistical analysis, and calibration of examiners. ${ }^{15,16}$ The total score was calculated for each study and the results regarding quality were evaluated and considered, as follows: $<7$ points, high risk of bias (not reviewed); 7 to 10 points, moderate risk of bias; and $>10$ points, low risk of bias. Moreover, the strengths and weakness of all the included studies were assessed according to Cochrane Reviewers' Handbook. ${ }^{5}$

\section{Discussion}

\section{Description of Studies}

Initially, 69 articles were selected from PubMed and 2 from Cochrane Library. Of these, 30 were excluded based on the title and 12 were excluded based on the abstract, with 29 retrieved for complete reading. Then, 7 articles were excluded because of the methodological quality of the studies and 6 because the study did not address the research question. A total of 13 articles and 1 systematic review were considered eligible for further review and inclusion in this study. The article selection process is charted in -Fig. $\mathbf{1}$.

There was no disagreement about study inclusion between reviewers. The most important limitation of this study is the heterogeneity of the articles, due to differences in disease severity and how the authors defined treatment success. - Table 1 lists the studies reviewed by the authors in relation anthropometric and physiologic factors. ${ }^{16-21}$

No randomized controlled trials addressing cephalometric and anatomical factors were found to be included in this

Table 1 Studies in relation to anthropometric and physiologic factors

\begin{tabular}{|l|l|}
\hline Author & Defined treatment success \\
\hline Barnes et al $^{17}$ & $\begin{array}{l}\text { Mild to moderate disease severity. In patients with mild to moderate OSAS, authors found that CPAP } \\
\text { and MRA effectively treated sleep-disorder breathing and sleepiness; however, the expected response } \\
\text { in neurobehavioral function was incomplete. This may be due to MRA having a lesser therapeutic } \\
\text { effect and CPAP being poorly tolerated (used less in this patient group). }\end{array}$ \\
\hline Engelman et al ${ }^{18}$ & $\begin{array}{l}\text { Mixed disease severity. Objective sleepiness, cognitive performance, and preference for treatment } \\
\text { were not different. In patients treated with CPAP versus MRA experiencing a mild form of the syndrome } \\
\text { (AHI }<15, n=18), \text { symptoms, treatment efficacy satisfaction, and subjective sleepiness were better } \\
\text { with CPAP than MRA. These results do not support the MRA as first-line treatment for patients with } \\
\text { OSAS. }\end{array}$ \\
\hline Hoekema et al ${ }^{19}$ & $\begin{array}{l}\text { Mixed disease severity. MRA therapy was less effective in individuals with severe disease (AHI }>30) . \\
\text { Because these patients could be at particular risk for cardiovascular disease, primary MRA therapy } \\
\text { appears to be supported only for those with nonsevere apnea. }\end{array}$ \\
\hline Metha et al & $\begin{array}{l}\text { Mixed disease severity. MRA used in this study was well tolerated, at least in the short term, and was } \\
\text { associated with substantial subjective and objective improvements in a significant proportion of } \\
\text { patients. These results support the use of MRA even in some of the patients with more severe forms of } \\
\text { OSAS. }\end{array}$ \\
\hline Tan et al & $\begin{array}{l}\text { Mild to moderate disease severity. (1) MRA may be a suitable alternative to nasal CPAP in patients with } \\
\text { mild to moderate OSAS; (2) larger studies on the long-term efficacy of the MRA will be required before } \\
\text { MRA can be offered as definitive alternative to nasal CPAP; (3) MRAs were well tolerated and preferred } \\
\text { by the majority of patients. }\end{array}$ \\
\hline Wilhemson et al & $\begin{array}{l}\text { Mild to moderate disease severity. Findings suggest that the MRA is useful in the treatment of mild to } \\
\text { moderate OSAS. }\end{array}$ \\
\hline
\end{tabular}

Abbreviations: AHI, apnea-hypopnea index; CPAP, continuous positive airway pressure therapy; MRA, mandibular repositioning appliance; OSAS, obstructive sleep apnea syndrome. 
review. Factors related to MRA (titratable, vertical dimension, and amount of advance), anthropometric and physiologic factors and MRA (titratable, vertical dimension and amount of advance), and the study founded in Cochrane Systematic Review are shown in - Table $\mathbf{2}^{5,23-29}$

\section{Summary of Evidence}

MRAs are widely prescribed for the treatment of OSAS both as primary therapy and as an alternative for patients who are unable to tolerate continuous positive airway pressure therapy. Although significant progress has been made in demonstrating the efficacy of MRA for OSAS, numerous methodologic weaknesses in published studies bring uncertainty about the role of this therapy in the routine management of OSAS. Until the mid to late 1990s, the majority of studies on the use of MRA in OSAS were short term, not controlled, small, and retrospective. More recently, the quality of MRA clinical research has become more rigorous. ${ }^{20}$

This review identified 13 randomized controlled trials with low or moderate methodologic quality involving participants with varied degrees of OSAS severity and 1 systematic review. However, the evidence to support the ability to predict treatment outcome and hence to preselect suitable candidates for this treatment option still remains in its early stages of development.

\section{Predictors of Response to the MRA}

The reviewed studies identified a range of anthropomorphic, physiologic, and PSG variables associated with better treatment outcome. Practice parameters developed by the

Table 2 Factors related to MRA, anthropometric and physiologic factors, and the study found in Cochrane Systematic Review

\begin{tabular}{|c|c|c|c|c|c|}
\hline \multicolumn{2}{|c|}{ Factors related to MRA only } & \multicolumn{2}{|c|}{$\begin{array}{l}\text { Anthropometric and physiologic factors and } \\
\text { MRA }\end{array}$} & \multicolumn{2}{|c|}{ Cochrane Systematic Review } \\
\hline Author & Description & Author & Description & Author & Description \\
\hline Araab et $\left.a\right|^{23}$ & $\begin{array}{l}\text { In patients with mild to } \\
\text { moderate condition ti- } \\
\text { tratable during PSG, the } \\
\text { authors found no differ- } \\
\text { ences in excessive day- } \\
\text { time sleepiness } \\
\text { improvements (MRA x } \\
\text { nCPAP). This would indi- } \\
\text { cate that the larger im- } \\
\text { provements in AHI in the } \\
\text { nCPAP group are not } \\
\text { clinically relevant. nCPAP } \\
\text { patients may show more } \\
\text { problems in accepting } \\
\text { nCPAP than MRA } \\
\text { patients. }\end{array}$ & $\begin{array}{l}\text { Gagnodoaux } \\
\text { et } \mathrm{al}^{26}\end{array}$ & $\begin{array}{l}\text { Titrated MRA is an effec- } \\
\text { tive therapy in moder- } \\
\text { ately sleepy and } \\
\text { overweight patients with } \\
\text { OSAS. Although less } \\
\text { effective than CPAP, suc- } \\
\text { cessfully titrated MRA } \\
\text { was very effective at re- } \\
\text { ducing the AHI and was } \\
\text { associated with a higher } \\
\text { reported compliance. } \\
\text { Both treatments im- } \\
\text { proved functional out- } \\
\text { comes to a similar } \\
\text { degree. One night of ti- } \\
\text { tration of MRA had a low } \\
\text { negative predictive value } \\
\text { for treatment success. }\end{array}$ & et $\mathrm{al}^{5}$ & $\begin{array}{l}\text { The review found } 16 \\
\text { studies that met the } \\
\text { inclusion criteria, com- } \\
\text { paring treatment with } \\
\text { oral appliances. The } \\
\text { authors suggest that } \\
\text { future research should } \\
\text { recruit patient with } \\
\text { more severe symptoms, } \\
\text { to establish whether the } \\
\text { response to therapy dif- } \\
\text { fers between } \\
\text { subgroups. }\end{array}$ \\
\hline Araab et $a^{24}$ & $\begin{array}{l}\text { No clinically relevant dif- } \\
\text { ference was found be- } \\
\text { tween MRA and nCPAP in } \\
\text { the treatment of mild/ } \\
\text { moderate OSA when } \\
\text { both treatment modali- } \\
\text { ties are titrated } \\
\text { objectively; }\end{array}$ & Petri et $\mathrm{al}^{27}$ & $\begin{array}{l}\text { MRA had significantly } \\
\text { beneficial effects on OSA, } \\
\text { including cure in some } \\
\text { cases of severe OSA. Pro- } \\
\text { trusion of the mandible is } \\
\text { essential for the effect. } \\
\text { MRA had no placebo ef- } \\
\text { fect and may be a good } \\
\text { alternative to CPAP. }\end{array}$ & & \\
\hline \multirow[t]{2}{*}{ Pitsis et $\mathrm{al}^{25}$} & \multirow[t]{2}{*}{$\begin{array}{l}\text { The amount of bite } \\
\text { opening induced by MRA } \\
\text { does not have a signifi- } \\
\text { cant impact on treatment } \\
\text { efficacy but does have an } \\
\text { impact on patient } \\
\text { acceptance. }\end{array}$} & Tegelberg et al ${ }^{28}$ & $\begin{array}{l}\text { MRA recommended for } \\
\text { patients of mild to mod- } \\
\text { erate OSAS but recom- } \\
\text { mended to not start the } \\
\text { treatment by more than } \\
50 \% \text { of mandibular } \\
\text { advancement. }\end{array}$ & & \\
\hline & & $\begin{array}{l}\text { Walker-Engstron } \\
\text { et } \mathrm{al}^{29}\end{array}$ & $\begin{array}{l}\text { MRA could be an alter- } \\
\text { native treatment for } \\
\text { some patients with } \\
\text { severe OSAS. }\end{array}$ & & \\
\hline
\end{tabular}

Abbreviations: AHI, apnea-hypopnea index; CPAP, continuous positive airway pressure therapy; MRA, mandibular repositioning appliance; nCPAP, nasal continuous positive airway pressure therapy; OSAS, obstructive sleep apnea syndrome; PSG, polysomnography. 
American Academy of Sleep Medicine recommend the use of MRAs only for those patients with mild OSAS or those who refuse or cannot tolerate continuous positive airway pressure therapy. Several studies support this conclusion. However, there is growing evidence supporting an expansion of use of MRAs in more severe forms of OSA, provided that patients are followed cautiously and objective verification of outcome is monitored. The pretreatment AHI, which reflects disease severity, has been suggested as a possible indicator of treatment effect in OSAS patients, with generally higher index levels suggesting treatment failure. ${ }^{20,30-33}$ The positive effect of the dental appliance was also independent of whether the predominant obstruction was in the oropharynx, the hypopharynx, or both.

Some evidence indicates that moderate to severe OSAS is closely associated with obesity and indicates that the dental appliance is an effective treatment in obese patients. ${ }^{29,34}$

Further work is required to determine the most effective design and vertical dimension opening of MRAs as a predictor of treatment success. The majority of the studies have compared devices of different design. ${ }^{20,25,35,36}$

The differences in results may be due to differences in the study design, in the way the MRA was titrated, in the baseline characteristics of the studies participants (e.g., the severity of OSA), in the primary outcome variable chosen, or in the specifics of the appliances and devices used. At least in part this uncertainty is related to how treatment success is defined and what factors can be clinically used as predictors of success. $^{37-41}$

The results of this review justify well-designed, largescale, randomized controlled trials to assess the effectiveness of MRA treatment.

\section{Conclusion}

This review of the published literature suggests that it is unclear which factors can be used with confidence to select patients suitable for OSAS treatment with MRAs. We are only able to make some assertions:

- Implications of this review for clinical practice: In the absence of clear predictors of MRA success, it would seem critical to monitor all subjects who have had an MRA fitted with a further overnight sleep study to make sure that the appliance provides satisfactory control of the disease.

- Implication of this review for research: Although significant progress has been reported in proving the efficacy of MRA for OSAS, the ability to predict treatment outcome and hence to preselect suitable candidates for this treatment still remains in its early stages. The review of these clinical trials suggests that there is need to conduct more randomized control trials comparing MRA with not only other treatments as controls but also placebo controls. Numerous methodologic weaknesses in published studies bring uncertainty about the role of this therapy in the routine management of OSAS.

\section{References}

1 Sleep-related breathing disorders in adults: recommendations for syndrome definition and measurement techniques in clinical research. The Report of an American Academy of Sleep Medicine Task Force. Sleep 1999;22(5):667-689

2 Berry RB, Budhiraja R, Gottlieb DJ, et al; American Academy of Sleep Medicine. ; Deliberations of the Sleep Apnea Definitions Task Force of the American Academy of Sleep Medicine. Rules for scoring respiratory events in sleep: update of the 2007 AASM Manual for the Scoring of Sleep and Associated Events. J Clin Sleep Med 2012;8(5):597-619

3 Tufik S, Santos-Silva R, Taddei JA, Bittencourt LRA. Obstructive sleep apnea syndrome in the Sao Paulo Epidemiologic Sleep Study. Sleep Med 2010;11(5):441-446

4 Young T, Palta M, Dempsey J, Skatrud J, Weber S, Badr S. The occurrence of sleep-disordered breathing among middle-aged adults. N Engl J Med 1993;328(17):1230-1235

5 Lim J, Lasserson TJ, Fleetham J, Wright J. Oral appliances for obstructive sleep apnoea. Cochrane Database Syst Rev 2006;(1): CD004435

6 Sateia MJ. Neuropsychological impairment and quality of life in obstructive sleep apnea. Clin Chest Med 2003;24(2):249-259

7 Alchanatis M, Zias N, Deligiorgis N, Amfilochiou A, Dionellis G, Orphanidou D. Sleep apnea-related cognitive deficits and intelligence: an implication of cognitive reserve theory. J Sleep Res 2005; 14(1):69-75

8 Shahar E, Whitney CW, Redline S, et al. Sleep-disordered breathing and cardiovascular disease: cross-sectional results of the Sleep Heart Health Study. Am J Respir Crit Care Med 2001; 163(1):19-25

9 Marin JM, Carrizo SJ, Vicente E, Agusti AGN. Long-term cardiovascular outcomes in men with obstructive sleep apnoea-hypopnoea with or without treatment with continuous positive airway pressure: an observational study. Lancet 2005;365(9464): 1046-1053

10 Marshall NS, Wong KK, Liu PY, Cullen SR, Knuiman MW, Grunstein RR. Sleep apnea as an independent risk factor for all-cause mortality: the Busselton Health Study. Sleep 2008;31(8): 1079-1085

11 Freedman N. Treatment of obstructive sleep apnea syndrome. Clin Chest Med 2010;31(2):187-201

12 American Academy of Sleep Medicine. International Classification of Sleep Disorders: Diagnostic and Coding Manual (ICSD-2). 2nd ed. Westchester, IL, USA: American Academy of Sleep Medicine; 2005

13 Chaves Junior CM, Dal-Fabbro C, de Bruin VMS, Tufik S, Bittencourt LRA. Brazilian consensus of snoring and sleep apnea-aspects of interest for orthodontists. Dental Press J Orthod 2011;16:e1-e10

14 Lacasse Y, Bureau MP, Sériès F. A new standardised and selfadministered quality of life questionnaire specific to obstructive sleep apnoea. Thorax 2004;59(6):494-499

15 Esposito M, Worthington HV, Coulthard P. In search of truth: the role of systematic reviews and meta-analyses for assessing the effectiveness of rehabilitation with oral implants. Clin Implant Dent Relat Res 2001;3(2):62-78

16 Roccuzzo M, Bunino M, Needleman I, Sanz M. Periodontal plastic surgery for treatment of localized gingival recessions: a systematic review. J Clin Periodontol 2002;29(Suppl 3):178-194, discussion 195-196

17 Barnes M, McEvoy RD, Banks S, et al. Efficacy of positive airway pressure and oral appliance in mild to moderate obstructive sleep apnea. Am J Respir Crit Care Med 2004;170(6):656-664

18 Engleman HM, McDonald JP, Graham D, et al. Randomized crossover trial of two treatments for sleep apnea/hypopnea syndrome: continuous positive airway pressure and mandibular repositioning splint. Am J Respir Crit Care Med 2002;166(6): 855-859 
19 Hoekema A, Stegenga B, Wijkstra PJ, van der Hoeven JH, Meinesz AF, de Bont LGM. Obstructive sleep apnea therapy. J Dent Res 2008; 87(9):882-887

20 Mehta A, Qian J, Petocz P, Darendeliler MA, Cistulli PA. A randomized, controlled study of a mandibular advancement splint for obstructive sleep apnea. Am J Respir Crit Care Med 2001;163(6): 1457-1461

21 Tan YK, L'Estrange PR, Luo Y-M, et al. Mandibular advancement splints and continuous positive airway pressure in patients with obstructive sleep apnoea: a randomized cross-over trial. Eur J Orthod 2002;24(3):239-249

22 Wilhelmsson B, Tegelberg A, Walker-Engström ML, et al. A prospective randomized study of a dental appliance compared with uvulopalatopharyngoplasty in the treatment of obstructive sleep apnoea. Acta Otolaryngol 1999;119(4):503-509

23 Aarab G, Lobbezoo F, Hamburger HL, Naeije M. Oral appliance therapy versus nasal continuous positive airway pressure in obstructive sleep apnea: a randomized, placebo-controlled trial. Respiration 2011;81(5):411-419

24 Aarab G, Lobbezoo F, Heymans MW, Hamburger HL, Naeije M. Long-term follow-up of a randomized controlled trial of oral appliance therapy in obstructive sleep apnea. Respiration 2011; 82(2):162-168

25 Pitsis AJ, Darendeliler MA, Gotsopoulos H, Petocz P, Cistulli PA. Effect of vertical dimension on efficacy of oral appliance therapy in obstructive sleep apnea. Am J Respir Crit Care Med 2002;166(6): 860-864

26 Gagnadoux F, Fleury B, Vielle B, et al. Titrated mandibular advancement versus positive airway pressure for sleep apnoea. Eur Respir J 2009;34(4):914-920

27 Petri N, Svanholt P, Solow B, Wildschiødtz G, Winkel P. Mandibular advancement appliance for obstructive sleep apnoea: results of a randomised placebo controlled trial using parallel group design. J Sleep Res 2008;17(2):221-229

28 Tegelberg A, Walker-Engström ML, Vestling O, Wilhelmsson B. Two different degrees of mandibular advancement with a dental appliance in treatment of patients with mild to moderate obstructive sleep apnea. Acta Odontol Scand 2003;61(6):356-362

29 Walker-Engström ML, Ringqvist I, Vestling O, Wilhelmsson B, Tegelberg A. A prospective randomized study comparing two different degrees of mandibular advancement with a dental appliance in treatment of severe obstructive sleep apnea. Sleep Breath 2003;7(3):119-130
30 Schmidt-Nowara W, Lowe A, Wiegand L, Cartwright R, PerezGuerra F, Menn S. Oral appliances for the treatment of snoring and obstructive sleep apnea: a review. Sleep 1995;18(6):501-510

31 O'Sullivan RA, Hillman DR, Mateljan R, Pantin C, Finucane KE. Mandibular advancement splint: an appliance to treat snoring and obstructive sleep apnea. Am J Respir Crit Care Med 1995;151(1): 194-198

32 Lowe A, Fleetham J, Ryan F, Mathews B. Effects of a mandibular repositioning appliance used in the treatment of obstructive sleep apnea on tongue muscle activity. Prog Clin Biol Res 1990; 345:395-404, discussion 405

33 Eveloff SE, Rosenberg CL, Carlisle CC, Millman RP. Efficacy of a Herbst mandibular advancement device in obstructive sleep apnea. Am J Respir Crit Care Med 1994;149(4 Pt 1):905-909

34 Millman RP, Rosenberg CL, Carlisle CC, Kramer NR, Kahn DM, Bonitati AE. The efficacy of oral appliances in the treatment of persistent sleep apnea after uvulopalatopharyngoplasty. Chest 1998;113(4):992-996

35 Bloch KE, Iseli A, Zhang JN, et al. A randomized, controlled crossover trial of two oral appliances for sleep apnea treatment. Am J Respir Crit Care Med 2000;162(1):246-251

36 Rose EC, Staats R, Lehner M, Jonas IE. Cephalometric analysis in patients with obstructive sleep apnea. Part I: diagnostic value. J Orofac Orthop 2002;63(2):143-153

37 Ferguson KA, Cartwright R, Rogers R, Schmidt-Nowara W. Oral appliances for snoring and obstructive sleep apnea: a review. Sleep 2006;29(2):244-262

38 Liu Y, Lowe AA, Fleetham JA, Park Y-C. Cephalometric and physiologic predictors of the efficacy of an adjustable oral appliance for treating obstructive sleep apnea. Am J Orthod Dentofacial Orthop 2001;120(6):639-647

39 Marklund M, Stenlund H, Franklin KA. Mandibular advancement devices in 630 men and women with obstructive sleep apnea and snoring: tolerability and predictors of treatment success. Chest 2004; 125(4):1270-1278

40 Randerath WJ, Heise M, Hinz R, Ruehle KH. An individually adjustable oral appliance vs continuous positive airway pressure in mild-to-moderate obstructive sleep apnea syndrome. Chest 2002;122(2):569-575

41 Ahrens A, McGrath C, Hägg U. Subjective efficacy of oral appliance design features in the management of obstructive sleep apnea: a systematic review. Am J Orthod Dentofacial Orthop 2010;138(5): 559-576

The author name and affiliation of José Faibes Lubianca Neto were corrected in this article according to the Erratum published online on October 3, 2015 (DOI: 10.1055/s-0035-1562934). 